\title{
Grupo de Apoio aos Enlutados pelo Suicídio:

\author{
uma experiência de posvenção e suporte \\ social
}

\author{
Support Group to the Bereaved by Suicide: an \\ experience of postvention and social support
}

\begin{abstract}
RESUMO
O tabu e o estigma produzidos culturalmente em torno do suicídio impõem interdições e sanções no processo de luto dos sobreviventes do suicídio, o que implica em uma dificuldade na simbolização da perda, devido ao não reconhecimento e validação social desse tipo de morte. Estas características particulares denunciam a falha de suporte social ao sobrevivente enlutado por suicídio que pode contribuir com o intenso sofrimento vivido e para a complicação na elaboração do luto. O presente artigo tem como finalidade apresentar um relato de experiência de pósvenção do suicídio com o Grupo de Apoio aos Enlutados pelo Suicídio, abordando a importância deste espaço para a promoção de um suporte social que habitualmente é frágil ou inexistente no processo de luto destes sobreviventes por suicídio. Esta experiência evidencia o grupo de apoio como um importante espaço para elaboração do luto por suicídio, onde o pesar e o sofrimento são expressos e validados, possibilitando que os enlutados possam encontrar um lugar de fala e pertencimento entre os pares.
\end{abstract}

Keywords: Luto - Sobreviventes - Grupos de apoio - Suicídio

\begin{abstract}
The culturally produced taboo and stigma surrounding suicide impose interdictions and sanctions on the grief process of the survivors' bereaved by suicide, which implies a difficulty in symbolizing their loss due to the non-recognition and social validation of this type of death. These particular characteristics denounce the failure of a social support to the suicide survivor that may contribute with the intense suffering and a complication in the mourning process. The purpose of this article is to present an experience of suicide postvention with the Suicide Bereavement Support Group, bringing to the discussion the importance of this space for the promotion of a social support that is usually fragile or non-existent in the process of mourning of these suicide survivors. This experience evidences the support group as an important space for the elaboration of suicide bereavement, where grief and suffering are expressed and validated, allowing mourners to find a place of speech and belonging among peers.
\end{abstract}

Keywords: Grief - Survivors - Suicide - Support groups - Bereavement

* Doutora em Psicologia Escolar e do Desenvolvimento Humano pela Universidade de São Paulo. CV Lattes: http://lattes.cnpq.br/4253380888161405.

** Mestre em Ciências da Saúde pela Universidade Federal de São Paulo. CV Lattes: http://lattes.cnpq. $\underline{\mathrm{br} / 1123975051130587 .}$.

*** Mestre Profissional em Ciências da Saúde pela Universidade Federal de São Paulo. CV Lattes: http:// lattes.cnpq.br/9939369074412215. 


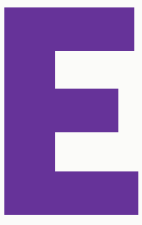

ste artigo contém relatos de experiência do nosso trabalho com grupos de apoio aos sobreviventes enlutados pelo suicídio. Em diálogo com o referencial teórico, pretendemos discutir as práticas em posvenção do suicídio, trazendo reflexões desenvolvidas ao longo destes cinco anos.

A morte por suicídio costuma ser o desfecho de um processo de intenso sofrimento que ocorre a partir de múltiplos fatores. Além disso, é um evento que resulta em dor e luto para os que permanecem e, como consequência, uma série de dificuldades podem ser observadas em vários âmbitos como, sociais, econômicos, psicológicos, legais, etc. Os fenômenos da morte e do suicídio têm seus significados construídos social e historicamente de modo que, em cada período histórico, distintas concepções determinaram atitudes e discursos frente a tais fenômenos.

Em uma breve retomada histórica, a percepção e a atitude do homem ocidental diante da morte passaram por uma mudança gradual evidenciada por Ariès (2012). Do periodo compreendido da Antiguidade Clássica à Idade Contemporânea, a morte passou de um evento familiar, público e esperado pelo moribundo, a um evento ocorrido de forma escamoteada, nos hospitais e de maneira controlada.

Para Ariès (2012, p. 270), nas sociedades mais industrializadas, "a morte tomou o lugar da sexualidade como interdito maior". Como a morte passou a ser tabu para o Ocidente, o suicídio é o tipo de morte com mais interditos, que está permeada por tabus culturais, religiosos e sociais (Scavacini, 2018b). Em um breve retrospecto histórico, Alvarez (1999) aponta que nas sociedades primitivas, acreditava-se que o suicídio de um indivíduo poderia torná-lo imortal ou ser fonte de vingança, atraindo a morte de um inimigo. O suicídio também fazia parte de alguns costumes tribais para o livramento de desonras, a fuga da escravidão, uma reação às perdas afetivas ou evitar a sobrecarga para seu povo com as limitações da idade avançada. Segundo Marquetti, o suicídio na Antiguidade Clássica, entre os gregos e romanos, estava relacionado a certos significados, como "vergonha, desonra, dor, fraqueza de caráter ou loucura momentânea" e havia uma diferença de gênero para as motivações ao ato (2018, p. 144). Neste período, o valor social pertencia ao Estado e era necessário que as autoridades consentissem o suicídio. O desrespeito dessa norma era suscetível a punições com o impedimento de ritos fúnebres e decepamento da mão direita que era enterrada à parte (Alvarez, 1999). Na Idade Média, o suicídio passar a ser visto sob o paradigma da religião. O corpo de quem se matasse poderia sofrer punições, como a forca. Com a ideia de pecado em Santo Agostinho, rejeitar a vida seria o mesmo que rejeitar a vontade de Deus. É na Idade Moderna que aparece, pela primeira vez, o neologismo "suicídio" (sui - de si próprio - e caedere - matar), que passou a substituir o termo até então utilizado "homicídio de si próprio", rompendo com o olhar religioso frente ao ato e trazendo um olhar existencial e humanizado para a questão (Minois, 1998). Após a Revolução Industrial, a partir do século XIX, há profundas mudanças na base da sociedade e o suicídio passa de um julgamento moral, religioso ou legal para um problema científico. Com a apropriação do suicídio como objeto de estudos nas ciências, nota-se o crescimento de um discurso médico sobre a questão, adquirindo uma concepção de caráter patológico, assim "o suicídio e as desordens mentais passaram a ser indissociáveis" (Lopes, 2008, p. 35). 
Falar a respeito dos sentidos históricos, culturais e sociais que atravessam o fenômeno também significa uma compreensão do processo de luto da morte autoinfligida. Uma vez que parte destas concepções ainda influencia o entendimento do suicídio, é comum que os sobreviventes enlutados pelo suicídio relatem interdições em seu processo de enlutamento (Scavacini, 2018a). Devido os preconceitos culturais e sociais em torno do fenômeno, há uma dificuldade de validação e, consequentemente, da expressão do luto por parte destes enlutados, que muitas vezes se sentem pressionados a não revelar a causa da morte, silenciando sua dor. Ariès (2012, p. 88) aponta que "o recalque da dor, a interdição de sua manifestação pública e a obrigação de sofrer só e às escondidas agravam o traumatismo devido à perda de um ente querido".

A Organização Mundial de Saúde (OMS, 2010) estima que para cada morte por suicídio, uma média de 5 a 10 pessoas são severamente afetadas, emocional, financeira e socialmente. No Brasil há em média 72.247 pessoas afetadas pelo suicídio por ano, o que evidencia a importância desta temática. Diversos são os estigmas que os enlutados por suicídio passam a enfrentar após este evento. Nesse sentido, Worden observa que, devido ao tabu:

Os sobreviventes são os que têm de sofrer a vergonha depois que um membro da família tira sua própria vida e esse senso de vergonha pode ser influenciado pelas reações dos outros. "Ninguém conversará comigo", disse uma mulher, cujo filho se matou. "Eles agem como se isso nunca tivesse acontecido". Essa pressão emocional adicional não apenas afeta a interação dos sobreviventes com a sociedade, como também pode alterar dramaticamente os relacionamentos dentro da unidade familiar (Worden, 2013, p. 130).

Trata-se de um enlutamento com maior duração e intensidade, que possui especificidades que serão abordadas adiante. $O$ presente artigo tem como finalidade apresentar uma experiência de posvenção do suicídio com o Grupo de Apoio aos Enlutados pelo Suicídio, apresentando a importância deste espaço para a promoção de um suporte social que habitualmente é frágil ou inexistente no processo de luto destes sobreviventes por suicídio.

\section{Especificidades do luto por suicídio}

O luto é um processo psicossocial e uma reação natural a uma perda significativa que exige um período para sua reorganização. Este processo é permeado por sentimentos e reações que variam de acordo com a relação que o enlutado tinha com o falecido, com o tipo de morte ocorrida, com o momento de vida deste falecimento e, por fim, com a rede de apoio, fé ou o modo como o enlutado lida com perdas. A maneira como cada um reage à perda também varia de acordo com a cultura, as representações sociais e as atitudes da sociedade em relação ao fenômeno (Kovács, 2010).

Em relação às particularidades do processo de luto por suicídio, Jordan \& McIntosh (2011) revelam que há, para os diferentes tipos de morte, semelhanças e diferenças. Os autores 
afirmam que, dividindo as mortes por subgrupos das mortes em geral; mortes inesperadas; mortes violentas e mortes por suicídio, suas semelhanças estariam na expressão da tristeza, saudade, dor pela perda. As particularidades para as mortes inesperadas seriam o choque, sensação de irrealidade e descrença, para as mortes violentas seria o trauma como principal característica e, para as mortes por suicídio, a presença da culpa, raiva do falecido, agressividade e sentimentos de rejeição e abandono.

Uma morte repentina como o suicídio costuma ser uma situação traumática, que pode gerar o que é nomeado de luto complicado, que ocorre quando há uma intensificação do luto até o ponto em que a pessoa se sente sobrecarregada ou permanece interminavelmente num estado de luto, sem progressão do processo em direção a sua evolução. Existem alguns indicadores de luto complicado, como por exemplo, quando, mesmo após um período significativo da morte, ainda persiste uma dificuldade de falar sobre a pessoa que faleceu sem vivenciar um luto recente e intenso, e a resistência em mexer nos pertences do falecido (Worden, 2013).

O luto por suicídio também pode ser entendido como "luto não reconhecido", no qual não há reconhecimento e validação social da perda, em função do estigma social da morte por suicídio (Silva, 2015). Aqui, trata-se de um fenômeno psicossocial onde a interdição social da expressão do sofrimento impede que o enlutado encontre espaço, tanto concreto quanto simbólico, para expressar seu pesar. Mais do que uma indiferença ao sofrimento, trata-se de sanções sociais que interferem para deslegitimar esse processo (Casellato, 2015).

Desta maneira, é frequente uma "conspiração do silêncio", que "causa grande dano à pessoa sobrevivente, que tem a necessidade de se comunicar com outras pessoas para resolver seu próprio luto" (Worden, 2013, p. 93). No luto por suicídio, de acordo com Silva (2015), a família sofre pela ausência de seu ente querido; pela falta de explicação sobre o que aconteceu; pelo julgamento social e pelo julgamento de si.

De Leo (2012, p. 07) afirma que o "suicídio é a pior de todas as tragédias humanas. Não apenas representa a culminância de um sofrimento insuportável para o indivíduo, mas também significa uma dor perpétua e um questionamento torturante, infindável para os que ficam". Ainda sobre o impacto na dinâmica familiar e social do enlutado, Kovács observa que:

O suicídio é uma das mortes mais difíceis de elaborar, pela forte culpa que desperta. Ativa a sensação de abandono e impotência em quem fica. O enlutado, além de lidar com a sua própria culpa, é frequentemente alvo de suspeita da sociedade como sendo o responsável pela morte do outro (Kovács, 1992, p. 160).

Em razão do tabu e estigma, a promoção de assistência e cuidados aos enlutados pelo suicídio foi negligenciada por muitos séculos, tendo suas primeiras ações datadas em meados 1960 na América do Norte. Não à toa, essas pessoas enlutadas e impactadas por um suicídio são chamadas de "sobreviventes", pois os estudos realizados até então sugerem que as reações psicológicas desse grupo são comparáveis às de pessoas que vivenciaram um estupro, passaram por uma guerra ou, ainda, foram vítimas de um crime violento (Fontenelle, 2008). No Brasil, 
o termo "sobrevivente enlutado pelo suicídio" é o mais utilizado para designar os enlutados, a fim de evitar confusão com a definição de pessoas que tentaram o suicídio e sobreviveram (Scavacini e Meleiro, 2018; Cornejo, 2018). Há uma vida antes e uma após o suicídio de alguém amado, nada será igual. Serão necessários uma ressignificação e reconstrução.

Bertolote (2012) aponta que os sobreviventes de um suicídio apresentam mais frequentemente sentimentos de responsabilidade pela perda do ente querido do que as pessoas que perderam alguém por causas naturais, além de sentirem mais vergonha e isolamento em comparação com os demais, especialmente quando se trata de pais que perderam seus filhos por suicídio. No mesmo sentido, Jamison aponta que:

O suicídio é uma morte como nenhuma outra, e aqueles que são deixados para lutar com isso devem enfrentar uma dor sem igual. Eles são deixados com o choque e o infindável "e se". São deixados com a raiva e a culpa [...]. São deixados para uma infinidade de perguntas dos outros, respondidas ou não, sobre o Motivo; são deixados ao silêncio dos outros, que estão horrorizados, embaraçados, e incapazes de formular um bilhete de pêsames, dar um abraço, fazer um comentário; e são deixados com os outros pensando - e eles também - que poderia ter sido feito mais (Jamison, 2010, p. 264).

A culpa é um sentimento comum na maioria dos sobreviventes enlutados. Segundo Clark "no início, os enlutados têm dificuldade para compreender que boa parte da culpa é imaginada, irreal. Acreditam, de maneira errada, que deveriam ter sido totalmente responsáveis pela vida do ente querido, controlando-a" (2007, p. 66).

A mídia em geral veicula a informação de que mais de $90 \%$ dos suicídios podem ser evitados, pois estariam relacionados a algum transtorno mental e, portanto, passível de prevenção. No entanto, embora trate-se de uma informação da OMS (2010), este dado tem sido refutado por especialistas, pois tem sua origem em estudos retrospectivos de "autópsia psicológica", nos quais é efetuada uma investigação pós-morte sobre os determinantes envolvidos em uma morte por suicídio. Para os sobreviventes esse é mais um fator gerador de estigma e julgamento, pois traz implícito que eles não foram capazes de prevenir aquela morte e, portanto, são culpados por não fazerem o que era necessário (Scavacini, 2018a).

Alguns enlutados referem sentimentos de desamparo e rejeição, como se pensassem que aquela pessoa se matou porque seu amor não foi suficiente para que ela permanecesse aqui. Embora a intencionalidade do comportamento suicida possa gerar discussões, o suicídio acaba por ser compreendido como uma morte que aconteceu por "escolha" do falecido. "A violência não diz respeito somente ao ato de tirar a própria vida, ou ao método utilizado, mas é também uma violência do gesto da própria pessoa que tira sua vida que, muitas vezes, endereça esse ato a alguém" (Silva, 2013, p. 62).

Outro sentimento frequente nos enlutados por suicídio é a raiva, que pode ter origem em diversos fatores: pela dor que estão enfrentando, pela perda, pela culpa, por ter de assumir um novo papel, pelo julgamento da sociedade. Ainda sobre a questão, Fontenelle pontua que: 
A raiva funciona como disfarce para substituir uma gama de sentimentos negativos. O mais comum é direcioná-la a quem se matou, porque ao mesmo tempo em que sentimos pena e tristeza em relação a quem morreu, o que dizer daquele que tirou a vida dessa mesma pessoa? É desse indivíduo que sentimos raiva. Choramos por quem foi e temos raiva da pessoa que provocou a morte (Fontenelle, 2008, p. 155).

O estigma social, a vergonha e o embaraço selam o isolamento da dor e silenciam o assunto. O suicídio se transforma em uma dor que não pode ser compartilhada. Em termos pessoais e sociais, é uma tragédia silenciosa e silenciada (Botega, 2015, p. 231).

Cabe ressaltar que não somente familiares, amigos e colegas de trabalho ou estudo podem sofrer este impacto. Como afirmam Scavacini \& Meleiro (2018), profissionais que acompanhavam a pessoa que consumou o suicídio também podem sofrer um luto pela perda do vínculo, pela responsabilidade que os familiares do paciente podem atribuir-lhes pelo falecimento, como também sentirem-se culpados por não terem conseguido evitar a morte.

De acordo com Scavacini (2017) é recomendado que as pessoas enlutadas por suicídio tenham acesso a cuidados e serviços apropriados às suas necessidades sempre que precisarem, com o objetivo de reduzir os efeitos potencialmente perigosos à saúde, cuidando também das ideações suicidas e do risco de suicídio dos sobreviventes, como forma de facilitar a construção de força, capacidade e resiliência. A Organização Mundial da Saúde recomenda que as autoridades sanitárias e de assistência social deem todo apoio à formação de grupos de ajuda mútua de sobreviventes do suicídio e apoiem sua manutenção (Bertolote, 2012, p. 121).

\section{Grupos de apoio a enlutados por suicídio}

A posvenção do suicídio, área que se dispõe a fornecer ações e atividades de cuidado aos sobreviventes enlutados por suicídio, pode acontecer de distintas formas. Os grupos de apoio aos enlutados por suicídio é uma das formas mais comuns no mundo de oferecer cuidado, acolhimento e suporte a sobreviventes enlutados (Scavacini, 2011). A World Health Organization (WHO, 2014) afirma que todo plano compreensivo de prevenção do suicídio deve incluir a posvenção em suas atividades.

De acordo com Botega (2015), enquanto os grupos de autoajuda iniciaram-se e tornaram-se frequentes depois da Segunda Guerra Mundial, foi em meados da década de 1970 que os grupos de apoio a pessoas enlutadas por suicídio surgiram na América do Norte. Os grupos de apoio permitem que os sobreviventes enlutados pelo suicídio troquem experiências com outros enlutados em um ambiente seguro, com empatia e sem julgamento. Para Silva:

Grupos permitem compartilhar o luto, possibilitam superar o estigma e a vergonha, são ambientes seguros para dividir a dor, reforçam a autoestima, ensinam que se enlutar é adequado, ajudam as pessoas a saber que não estão ficando loucas, a lidar com o que poderia ter sido evitado, a chorar e expressar sentimentos (Silva, 2015, p. 124). 
Existem diferentes formações de grupos de apoio, que podem variar quanto ao tipo, frequência, forma, participantes e etc.. Quanto ao tipo, os grupos podem ser coordenados por profissionais da área da saúde; por sobreviventes enlutados; por voluntários; ou por ambos: profissionais e sobreviventes. No que concerne à forma, os grupos podem ser abertos, permitindo a participação de novos membros ao longo dos encontros ou fechados, restringindo a participação de novos membros após os três primeiros encontros. Com relação à frequência, pode ser estabelecido um número total de encontros previamente, ou funcionar sem limite de encontros. Por fim, com relação aos participantes, é frequente a presença de pessoas com vínculos familiares e consanguíneos com o falecido, amigos próximos e profissionais enlutados.

De acordo com Yalom, os participantes de grupos específicos, como os de enlutados por suicídio, "podem falar uns dos outros com uma autenticidade poderosa que vem de sua experiência em primeira mão, de maneiras que os terapeutas talvez não consigam fazer" (2006, p. 28).

\section{A experiência de um grupo de apoio como ferramenta de suporte social}

O Grupo de Apoio aos Enlutados do Instituto Vita Alere de Prevenção e Posvenção do Suicídio, teve início no começo de 2014 e oferece encontros mensais e gratuitos na cidade de São Paulo/SP (em Moema) e, desde o início de 2017, também na Vila Mariana/SP, além das cidades de Santos/SP e Largo do Machado/RJ.

Este grupo de apoio não exige inscrição prévia para a participação, é coordenado por profissionais, funciona sem limite no número de encontros e recebe prioritariamente sobreviventes enlutados. Somente a partir de 2016 os sobreviventes de tentativas começaram a frequentar esporadicamente o grupo e, por essa razão, este trabalho está baseado na experiência com os sobreviventes enlutados pelo suicídio. Apesar de não ser um grupo terapêutico ao luto, o grupo de apoio pode desempenhar um papel terapêutico para os participantes e seus objetivos estão ligados ao apoio no processo de luto.

São objetivos do grupo de apoio a enlutados por suicídio: Promover um senso de comunidade, pertencimento e de apoio; Fornecer a conexão com outros sobreviventes, a esperança de se sentir melhor, a possibilidade de aprender novos comportamentos para problemas parecidos; Favorecer a expressão dos sentimentos, ter a sensação de ser compreendido e a abertura para compartilhar a dor em um lugar seguro, com suporte e sem julgamentos; Educar sobre o comportamento suicida e o processo de luto; Empoderar sobreviventes e disseminar o apoio e acolhimento para aqueles que precisam; Propiciar um ambiente empático e compreensivo para quem se sente isolado do resto do mundo; Oportunidade de aprender novas formas de lidar com o problema; Um local sólido e receptivo para discutir temores e preocupações; Um local onde possa expressar livremente seus sentimentos de luto, onde a confidencialidade está assegurada e onde prevalece uma atmosfera tolerante isenta de julgamentos (Bertolote, 2012, p. 121).

Os participantes que frequentam o grupo têm de 7 dias a 20 anos de enlutamento. 
A maioria deles teve conhecimento do espaço mediante indicação de outros psicólogos ou de buscas e divulgação pela internet. Encontramos neste grupo pessoas com diferentes tipos de vínculo com a pessoa que faleceu, como pais, esposas, irmãos, amigos. Por enquanto não há separação do grupo pelo tipo de vínculo. Quando há a presença de sobreviventes que tentaram suicídio oferecemos acolhimento, mas, por entendermos que há especificidades e demandas distintas para cada caso que necessitam ser trabalhadas separadamente, priorizamos a participação dos enlutados pelo suicídio.

A partir de nossa experiência, podemos referir quatro grupos de participantes observados: 1. Pessoas que se vinculam ao grupo e passam a vir a todos os encontros, fortalecendo o vínculo entre os facilitadores e demais participantes; 2 . Pessoas que veem somente uma vez, contam a história com mínimos detalhes, choram muito (catarse emocional) e não voltam mais; 3 . Pessoas que se sentem pior do que estavam, não conseguem escutar as outras histórias, lidar com sua dor e a do outro. Em geral estes participantes interrompem ou invalidam a fala dos demais ou mostram-se impactadas negativamente diante dos relatos do grupo; 4. Pessoas que já receberam o que precisavam, comparecem em alguns encontros, voltam esporadicamente ou não voltam mais por compreenderem que o processo no grupo foi finalizado.

Como a maior parte das atividades de interação social atualmente ocorrem na era digital, os membros do "Grupo de Apoio do Vita Alere" criaram um grupo de WhatsApp e, desta forma, conseguem estar conectados e dar suporte uns aos outros durante os intervalos dos encontros. Observamos que em datas específicas, como o dia do aniversário do falecido ou a data de sua morte, os enlutados tendem a mobilizar busca e oferta de apoio mútuo entre os participantes.

Os grupos de apoio do Vita Alere contam com uma dupla de profissionais de Psicologia como facilitadores dos encontros. Nestes é priorizado o espaço de fala dos enlutados e suas interações. Pontualmente, diante de uma dúvida dos participantes ou quando uma observação pode agregar às reflexões dos participantes, as psicólogas efetuam alguma intervenção, por exemplo, sobre o tempo e oscilações do processo de luto ou simplificações a respeito do comportamento suicida. Os participantes podem opinar quanto a tratar de um tema específico como, por exemplo, a culpa. Contudo, a demanda por espaço de fala é tão proeminente no grupo, a ponto de não ser necessário apresentar questões e temas prontos, pois eles emergem do grupo naquele encontro.

Ter espaço para elaborar a perda parece ser o mais importante para os enlutados. Sobre o tema, Bowlby refere que:

Evidentemente, para darmos à pessoa que sofre uma perda o tipo de ajuda que desejaríamos dar, é essencial vermos as coisas do seu ponto de vista e respeitarmos seus sentimentos [...]. Pois somente se a pessoa que sofre a perda sentir que podemos, pelo menos, compreendêla e simpatizar com ela nas tarefas que estabeleceu para si mesma, haverá a possibilidade de que expresse todos os sentimentos que estão fervilhando em seu íntimo [...]. O nosso papel deve ser, então, o de um companheiro pronto a oferecer todo o apoio, preparado para explorar, em nossas discussões, todas as esperanças e desejos e tênues 
possibilidades improváveis que a pessoa ainda acalenta, somados a todas as recriminações, remorsos e decepções que a afligem (Bowlby, 2015, p. 128-129).

Para o bom funcionamento do grupo, são utilizadas algumas etapas e um código de ética. As etapas marcam as atividades e ações realizadas de forma temporal. São elas: 1. Boas vindas: recepção dos participantes e preenchimento de uma ficha com dados pessoais; 2 . Introdução e regras: exposição do funcionamento da dinâmica do grupo e das regras que norteiam o encontro; 3. Compartilhamento de experiências: os participantes contam suas histórias e trocam experiências sobre o luto e a perda por suicídio; 4. Revisão do que foi falado, experienciado e como cada um está: as facilitadoras recapitulam pontos que consideram significativos e verifica como os participantes se encontram emocionalmente; e, por fim, 5 . Fechamento e ritual de despedida.

O código de ética utilizado foi desenvolvido pela facilitadora e baseado na própria experiência e nas dificuldades dos encontros. Ele é útil para orientação dos participantes no início de cada encontro, considerando que sempre é possível contar com pessoas que participam do grupo pela primeira vez e é entregue impresso para cada novo participante, para que ele possa rever o código com calma posteriormente. Estas regras ajudam a compreender o processo.

São elas: a) Por favor, tente chegar na hora; b) Tudo que for dividido pelos outros, deverá ficar aqui. Pedimos que você mantenha sigilo do que escutou. Você pode dividir com outros o que você sentiu e achou, mas não sobre as estórias que escutou; c) Muitas vezes aprendemos mais escutando a experiência de outros do que dando conselhos; d) Se respeite, fale e cale o que quiser. Aqui é um lugar seguro para conversarmos abertamente; e) Se você quiser saber mais sobre alguma coisa, pergunte. Por favor, não faça julgamentos dos outros e nem tente apontar falhas em algum pensamento ou comportamento dos outros. Esse não é o nosso objetivo; f) Respeite a opinião dos outros. Talvez o que não funciona para você, funciona para outra pessoa; g) Não tente medir o tamanho da dor de cada um. Todos estão sofrendo; h) Divida sua história, sua experiência. Mesmo que você não goste de como acabou, isso pode, quem sabe, ajudar outra pessoa a fazer de um jeito diferente; i) Todos nós cometemos erros; j) Seja respeitoso com o luto do outro, não interrompa; k) Ao oferecer suporte, compaixão e coragem para outros, eles farão o mesmo a você; l) Divida o tempo com todos, não monopolize; m) Não espere que os outros resolvam o seu problema ou te deem conselhos; n) Esteja aberto à ideia dos outros; o) Sua opinião sobre o funcionamento do grupo é bem-vinda. Aceitamos sugestões; p) Se precisar, peça ajuda!; q) Se dê uma chance, se você achar que o primeiro encontro não lhe ajudou, por favor, volte mais algumas vezes antes de decidir que esse espaço não é para você.

Em respeito aos participantes e para preservar ao máximo a confiança e acolhimento neste espaço de encontro, há muito cuidado em relação aos interessados em participar dos grupos, que não são sobreviventes enlutados ou de tentativas de suicídio, como profissionais de saúde, estudantes de Psicologia, etc. O acesso é restrito e, quando eventualmente algum 
participante não sobrevivente deseja participar, é realizada uma conversa com o grupo no encontro anterior para que sua presença seja permitida. Alguns participantes do grupo de apoio já iniciaram seus próprios grupos, o que reforça a importância desse trabalho como multiplicador de cuidado e de suporte social.

Quanto à dinâmica dos participantes, nota-se que em um grupo que está iniciando suas atividades, os facilitadores podem ter maior participação, explicando o funcionamento, fazendo intervenções ou controlando o tempo, por exemplo. Já em um grupo que acontece há mais tempo, mesmo com novos participantes, este apresenta um ritmo próprio, fluido, no qual uma parte das pessoas se reencontram, conhecem previamente a história do outro, sabem o tipo de apoio que receberão e, portanto, se sentem mais à vontade para compartilhar suas histórias. Os novos participantes podem se sentir intimidados ou ansiosos, em um primeiro momento, mas é possível perceber como suas expressões mudam ao longo do encontro, na medida em que se identificam com os relatos compartilhados pelo grupo.

De acordo com Yalom (2006, p. 27), ao ouvir relatos de outros participantes com experiências semelhantes, os membros do grupo podem sentir-se "mais em contato com o mundo". A universalidade de uma experiência tão complexa pode gerar alívio, empatia e empoderamento, para que os sobreviventes também sejam agentes de transformação na diminuição do tabu, no aumento de consciência pública e no acolhimento de outros sobreviventes, conforme caminharem em seu processo de luto e tiverem desejo de engajamento na área de prevenção do suicídio, fenômeno observado em vários participantes do grupo.

\section{Temas e sentimentos mais frequentes nos encontros}

A participação em grupos de apoio oferece a cada membro do grupo a oportunidade de beneficiar outras pessoas, ao alternar os papeis de receber e oferecer ajuda. Cada um pode oferecer ao outro apoio, sugestões e observações, sendo muito mais fácil que o grupo aceite comentários de outros participantes do que do facilitador (Yalom, 2006).

Temos observado em nossa experiência que os temas e sentimentos que aparecem com maior frequência nos encontros são: Culpa, autoacusação, busca do porquê, estigma; Raiva, frustração, abandono, tristeza profunda, desespero; Busca de informações sobre o comportamento suicida; Compartilhamento de materiais e livros que abordam a temática; Diferença na forma de enlutamento de cada membro da família; Dúvida sobre o processo de luto e os sentimentos; Luto pela perda da pessoa e por tudo que deixará de acontecer com ela no futuro; Ter ou não o direito a ser feliz novamente; Como transformar a dor e o sofrimento em saudade; Como eu estava e como eu estou (consciência do processo do luto); Busca da esperança, da paz e da serenidade; O que ajuda e o que dificulta o processo de luto; O que é igual e o que é diferente de outros tipos de morte; Contar ou não sobre o motivo da morte para os outros; Vontade de morrer por suicídio e medo que outros queiram morrer por suicídio; Como enfrentar datas comemorativas e de aniversário; Como honrar a memória de quem morreu. O que fazer com os pertences; Quando e se devo procurar um psiquiatra; Tabu em 
torno do suicídio; Crenças religiosas; Processo de investigação da causa da morte pela polícia; Reações a reportagens que abordam o suicídio; Ressignificação do sentido de vida.

\section{Dificuldades e desafios}

Em nosso trabalho com o grupo de enlutados por suicídio, nos deparamos com diversos desafios, dentre os quais há questões relacionadas ao processo de facilitação de um grupo de apoio e ao apoio social recebido pelos membros. São elas: Acolher os novos membros, os recém-enlutados e os membros antigos com cuidado para que todos possam falar durante o encontro e não haja monopolização do tempo; Abarcar as diferentes necessidades de cada processo, respeitando as singularidades e tempo desde a morte; Prover cuidado para que todos os membros saiam "bem" e estimular o autocuidado e respeito aos limites; Evitar a comparação e quantificação da dor de cada um; Capacitar sobreviventes e profissionais para coordenarem grupos; Oferecer grupos em diversas cidades; Criar uma plataforma virtual específica para grupos online; Divulgar o grupo, fazer com que os sobreviventes saibam que ele existe, conectar os sobreviventes ao serviço; Entender quais são as principais necessidades dos enlutados por suicídio em seu processo de luto e como o grupo de apoio pode ajudar esse processo; Fazer um acompanhamento com as pessoas que vieram somente uma vez, para checar como estão e fazer um feedback; Vontade de ajudar os sobreviventes de tentativas em um grupo especial para eles.

Nota-se que há escassez atualmente, tanto no apoio social para os enlutados pelo suicídio quanto no que concerne à formação para facilitadores de grupo de apoio. Muito do trabalho desenvolvido foi baseado na própria experiência dos facilitadores e na literatura internacional. Outros desafios para o desenvolvimento deste trabalho consistem em encontrar locais disponíveis e gratuitos para os encontros, realizar a divulgação dos encontros em grande escala, ter locais para encaminhamento dos participantes em vulnerabilidade, obter rede de apoio e compartilhamento entre facilitadores de grupos e, por fim, encontrar e/ou disponibilizar a formação de cofacilitadores.

\section{Conclusão}

A concepção do suicídio é construída social e historicamente, estando presente na base dos discursos e atitudes contemporâneas da sociedade diante da pessoa que tenta o suicídio e sua família, bem como frente ao falecido por suicídio e seus familiares enlutados. Dessa maneira, muitas são as questões agregadas ao processo de luto de um sobrevivente por suicídio, tais como o estigma social que lhes provoca silenciamento e o isolamento, a culpa e a vergonha diante do julgamento do outro, a dificuldade em simbolizar sua perda devido ao não reconhecimento e validação social do luto, além de outras dificuldades de cunho emocional, econômico ou jurídico. Todas essas questões denunciam a escassez de suporte social ao 
enlutado por suicídio e pode acarretar intenso sofrimento e complicações na elaboração do luto. Apesar do crescimento da área de posvenção no país, ainda há um muito trabalho para a ampliação deste tipo de cuidado, principalmente no que tange ao desenvolvimento de políticas públicas. Aumentar a consciência pública sobre as multideterminações do suicídio - a despeito do movimento majoritário em silenciar o assunto, ou buscar culpados e explicações simplistas para esse fenômeno complexo - pode contribuir para a diminuição do estigma, além de possibilitar uma elaboração do luto por suicídio com menos complicações.

Consideramos que falar abertamente sobre a morte, o luto e suas ramificações, em grupos, abertos e preparados, tem um papel benéfico para a sociedade e para os sobreviventes enlutados, e é fundamental na abertura de um espaço público e individual para que ocorra esse cuidado e não julgamento; para que elas existam perante uma sociedade como pessoas que sofrem e merecem respeito no seu processo de luto.

Observamos em nossa experiência com grupos de enlutados por suicídio, que este tem sido um importante espaço para elaboração do luto por suicídio. Os grupos permitem que o pesar e o sofrimento sejam expressos e validados, possibilitando que, entre pares, possam encontrar um lugar de fala e de realização concreta do seu enlutar. Dessa maneira, a vivência entre os participantes torna-se uma importante estratégia de posvenção e prevenção do suicídio, promovendo suporte social, acolhimento, empatia, pertencimento e, o mais importante, a reconstrução da vida após essa perda trágica. Os sobreviventes enlutados que têm participado dos grupos de apoio do Instituto Vita Alere ao longo destes anos nos têm ensinado muito sobre a importância do pertencimento e do acolhimento sem julgamento, experiência que nos mantém na defesa e apoio ao desenvolvimento de novos grupos de apoio.

\section{Referências Bibliográficas}

ALVAREZ, Al. O deus selvagem: um estudo do suicídio. São Paulo: Companhia das Letras, 1999. $287 p$.

ARIĖS, Philippe. História da morte no Ocidente: da Idade Média aos nossos dias. Trad. Priscila Viana de Siqueira. Rio de Janeiro: Nova Fronteira, 2012. 304p.

BERTOLOTE, José Manoel. O suicídio e sua prevenção. São Paulo: Ed. Unesp, 2012. 144p.

BOTEGA, Neury José. Crise suicida: avaliação e manejo. Porto Alegre: Artmed, 2015. 304p.

BOWLBY, John. Formação e rompimento dos laços afetivos. Trad. Álvaro Cabral. 5a Ed. São Paulo: Martins Fontes, 2015. 228p.

CASELLATO, Gabriela. Luto não reconhecido: o fracasso da empatia nos tempos modernos. In: ________ (Org.). O resgate da empatia: suporte psicológico ao luto não reconhecido. São Paulo: Summus, p. 15-28, 2015.

CLARK, Sheila. Depois do suicídio: apoio às pessoas em luto. Trad. Marcello Borges. São Paulo: Ed. Gaia, 2007. 136p. 
CORNEJO, Elis Regina Souza Peito Urtubia. Luto por suicídio: a jornada dos sobreviventes. In: SCAVACINI. Karen (Org.). Histórias de sobreviventes do suicídio. São Paulo: Instituto Vita Alere, Benjamin Editorial, p. 61-70, 2018.

DE LEO, Diego. Apresentação. In: BERTOLOTE, José Manoel. O suicídio e sua prevenção. São Paulo: Ed. Unesp, p. 7-13, 2012.

FONTENELLE, Paula. Suicídio: o futuro interrompido - guia para sobreviventes. São Paulo: Geração Editorial, 2008. 256p.

JAMISON, Key Redfield. Quando a noite cai: entendendo a depressão e o suicídio. Trad. Gilson B. Soares. 2ª. ed. Rio de Janeiro: Gryphus, 2010. 294p.

JORDAN, John; MCINTOSH, John. (org). Grief after suicide: understanding the consequences and caring for the survivors. Nova York: Routlegde, 2011.

KOVÁCS, Maria Júlia. Morte, separação, perdas e o processo de luto. In: (Coord.). Morte e desenvolvimento humano. São Paulo: Casa do Psicólogo, p. 153-169, 1992.

KOVÁCS, Maria Júlia. Morte e desenvolvimento humano. São Paulo: Casa do Psicólogo, 2010.

LOPES, Fábio Henrique. Suicídio \& saber médico: estratégias históricas de domínio, controle e intervenção no Brasil do século XIX. Rio de Janeiro: Apicuri, 2008. 210p.

MARQUETTI, Flávia Regina. O suicídio na Grécia Clássica: entre a espada e o laço. In: MARQUETTI, Fernanda Cristina. Suicídio: escutas do silêncio. São Paulo: Editora Unifesp, p.123-46, 2018.

MINOIS, Georges. História do Suicídio: a sociedade ocidental diante da morte voluntária. São Paulo: Editora Unesp, 2018.

OMS. Suicide Prevention (SUPRE). 2010. Disponível em: <http://www.who.int/mental_health/ prevention/suicide/suicideprevent/en/index.html>. Acesso em novembro de 2010.

SCAVACINI, Karen. Suicide survivors support services and postvention activities: The availability of services and an interventions plan in Brazil. Dissertation (Master Program in Public Health). Departament of Public Health Sciences, Karolinska Institutet, Stockholm, 2011.

SCAVACINI, Karen. Brazil - The development of Suicide Postvention. In: ANDRIESSEN, Karl; KRYSINSKA, Karolina \& GRAD, Onja (Eds.). Postvention in Action: The Internacional Handbook of Suicide Bereavement Support. Boston: Hogrefe, p. 271-276, 2017.

SCAVACINI, Karen. O suicídio é um problema de todos: a consciência, a competência e o diálogo na prevenção e posvenção do suicídio. Tese (Doutorado em Psicologia). Instituto de Psicologia, Universidade de São Paulo, São Paulo, 2018a.

SCAVACINI, Karen. Porque precisamos falar sobre o suicídio? In: (Ed.). Histórias de sobreviventes do suicídio. São Paulo: Benjamin Editorial \& Instituto Vita Alere, p. 7-21, 2018b.

SCAVACINI, Karen e MELEIRO, Alexandrina Maria Augusta da Silva. Posvenção: Sobreviventes do Suicídio. In: MELEIRO, Alexandrina Maria Augusta da Silva (Ed.). Psiquiatria: Estudos Fundamentais. Rio de Janeiro: Guanabara Koogan, p. 671-676, 2018. 
SILVA, Daniela Reis. Na trilha do silêncio: múltiplos desafios do luto por suicídio. In: CASELLATO, Gabriela (Org.). O resgate da empatia: suporte psicológico ao luto não reconhecido. São Paulo: Summus, p. 111-128, 2015.

SILVA, Lúcia Cecília. Capítulo V. In: CONSELHO FEDERAL DE PSICOLOGIA. O suicídio e os desafios para a Psicologia. Brasília: CFP, p. 59-64, 2013.

WORLD HEALTH ORGANIZATION. Preventing suicide: A Global Imperative. World Health Organization. Luxemburgo, 2014. 92p.

WORDEN, James William. Terapia no luto e na perda: um manual para profissionais de saúde mental. São Paulo: Roca, 2013. 248p.

YALOM, Irvin David. Psicoterapia de grupo: teoria e prática. Trad. Ronaldo Cataldo Costa. Porto Alegre: Artmed, 2006. 528p.

Enviado em: 29 de abril de 2019.

Aprovado em: 10 de julho de 2019. 